\title{
Trabalho e política para Ensinar História: apontamentos sobre a BNCC e a Educação Profissional e Tecnológica
}

\section{Work and politics to Teach History: appointments about the BNCC and Professional and Technological Education}

\author{
Bergston Luan Santos*
}

\begin{abstract}
RESUMO
Este texto busca iniciar uma reflexão sobre as categorias trabalho e política na Base Nacional Comum Curricular (BNCC) e como estão dispostas para formação em Ciências Humanas, locus macro da disciplina de História, problematizando a Educação Profissional e Tecnológica (EPT). Para tanto, o artigo está dividido em uma apresentação/introdução histórica sobre Educação Profissional no Brasil, discussão sobre as categorias trabalho e política na BNCC e considerações. Nesse sentido, apontamos que a Base necessita ser problematizada no contexto de sua elaboração e sugerimos que as categorias trabalho e política, induzidas pela Base, simplificam processos sociais que são complexos e que precisam ser reelaborados pelos docentes de maneira integrada, como é exigido na formação profissional tecnológica.

Palavras-chave: Formação histórica. Política. Trabalho e EPT.
\end{abstract}

\begin{abstract}
This paper reports an initial reflection on the Work and Politics categories in the Base Nacional Comum Curricular (BNCC) and how these are prepared for training in Human Sciences, macro locus of the History subject. Basically, the study questions the Educação Profissional e Tecnológica (EPT). Thus, the paper is divided into a historical presentation/introduction on Professional
\end{abstract}

* Instituto Federal Norte de Minas Gerais. Montes Claros, Minas Gerais. Brasil. E-mail: bergslash@yahoo.com.br - https://orcid.org/0000-0002-2315-3013 
Education in Brazil, discussion on the categories of Work and Politics in the BNCC and considerations. For this purpose, we have pointed out that the Base needs to be questioned in the context of its elaboration and we have suggested that the categories Work and Politics, induced by the Base, simplify social processes that are complex and need to be reformulated by teachers in an integrated manner according to technological professional training.

Keywords: Historical formation. Politics. Work and EPT.

\section{Introdução}

A instituição e expansão da rede de Educação Profissional e Tecnológica (EPT) contemplam ações políticas do segundo mandato do ex-presidente Luiz Inácio Lula da Silva (2007-2010), marcado por uma perspectiva explícita em assegurar a educação e, especificamente, a educação profissional e tecnológica nas Políticas Públicas do país (PACHECO, 2010). Afinal, como afirmam Frigotto, Ciavatta e Ramos (2005), tal situação não havia conseguido ser materializada no primeiro mandato do ex-presidente Lula (2003-2006).

Para Pacheco (2010), havia naquele contexto (2007-2010) uma preocupação com o debate relativo às transformações sofridas pela educação tecnológica durante a década de 1990, pois causaram a separação da educação técnica do Ensino Médio, a extinção dos cursos técnicos integrados, a criação e priorização dos Cursos Superiores de Tecnologia, a transformação das Escolas Técnicas em Centros de Educação Tecnológica, entre outras mudanças no âmbito da educação em geral. Tal conjuntura também era marcada pela disputa política em torno das discussões sobre a educação e o mundo do trabalho.

No entanto, é preciso explicitar que essa disputa não foi exclusiva a tal contexto, afinal, historicamente, a demanda de formação profissional desde o século XIX voltava-se para consolidação de formação de mão de obra que fosse capaz de atender à demanda do capital e servir à produção de bens para o consumo (MANACORDA, 2006). E isso não foi distinto, num âmbito geral, na formação histórica da educação profissional no Brasil. 
No país ${ }^{1}$, o breve período em que assumiu a presidência da República (1909-1910), Nilo Peçanha assinou o Decreto $n^{\circ} 7.566$ no ano de 1909 (BRASIL, 1909), criando as "Escolas de Aprendizes Artífices", destinadas ao ensino profissional, primário e gratuito. Para Sales e Oliveira (2011), um dos objetivos dessas escolas era ensinar jovens, crianças pobres, garotos de rua e delinquentes. Esse fato, segundo os autores, contribuiu para a percepção de que essa modalidade de ensino destinava-se somente a sujeitos pobres e periféricos. Ao encontro dessa argumentação, Vieira e Souza Junior (2016) afirmam que a educação profissional no Brasil nasceu revestida de uma perspectiva assistencialista com o objetivo de amparar os pobres desprovidos de condições sociais e econômicas.

Na década de 1970, a Lei $n^{\circ} 5.692 / 71$ (BRASIL, 1971) impôs o ensino médio profissionalizante. Nesse contexto, como apontado por Vieira e Souza Junior (2016), havia o interesse do Governo Militar (1964-1985) no desenvolvimento da industrialização do país, e esse projeto demandava mão de obra qualificada com técnicos de nível médio juntamente ao desenvolvimento industrial, situação marcada pela intensificação da internacionalização do capital. Segundo Benakouche (1980), houve um estágio no desenvolvimento do capitalismo caracterizado pela passagem da internacionalização da esfera da circulação (isto é, troca internacional, economia internacional) para a internacionalização da esfera de produção, fato que mudou as formas dominantes da produção no século XX.

Somente na segunda metade dos anos de 1990, a partir Lei ${ }^{\circ}$ 9.394/1996 (BRASIL, 1996), que estabelece as Diretrizes e Bases da Educação Nacional (LDB), é que o conceito de Educação Profissional passa a ser Tecnológica, ou como aponta o artigo 39 da referida Lei: "A educação profissional e tecnológica, no cumprimento dos objetivos da educação nacional, integra-se aos diferentes

1 Importante ressaltar que a Educação Profissionalizante (para o trabalho) para o público, os pobres e desvalidos é anterior ao Decreto de criação das Escolas de Aprendizes e Artífices. Afinal, durante grande parte do período Colonial (1500-1808), tivemos no território a desvalorização das atividades que envolviam trabalhos manuais. Os homens livres, no geral, rejeitavam a aprendizagem e a profissionalização em ofícios manuais, já que eram quase que exclusivamente realizados por mão de obra escravizada, e isso se estende no período chamado Imperial (1822-1889). Na denominada República (1889), continuou sendo atribuído aos trabalhadores pobres e ex-escravizados a condição quase exclusiva de realizar os ofícios manuais. Ainda podemos citar o exemplo, desde o período Imperial, da criação do Asilo dos Meninos Desvalidos (1874). Tratava-se de uma escola pública de instrução primária e profissional, destinada a servir de asilo para recolher os menores pobres que fossem encontrados vagando ou mendigando nos distritos da Corte. De certa maneira, o decreto que criou as Escolas de Aprendizes e Artífices (1909) veio reforçar algo que já se encontrava sedimentado no pensamento e na prática educacional brasileira. Ver (CUNHA, 1979, 2005). 
níveis e modalidades de educação e às dimensões do trabalho, da ciência e da tecnologia" (BRASIL, 1996). Para Vieira e Junior (2016), essa alteração tinha por objetivo redimensionar, institucionalizar e integrar as ações da educação profissional técnica de nível médio aos diferentes níveis e modalidades de educação e às dimensões do trabalho, da ciência, da tecnologia e da cultura.

Um fato que temos, considerando os autores e contextos citados, é que, desde as primeiras tentativas de se instituir a educação profissional no Brasil, a disputa em torno dos sujeitos e finalidades dessa modalidade de formação é explícita. Percebemos inicialmente um caráter moralizante/assistencialista sobre a educação pelo trabalho, no sentido de que tal modalidade deveria ser uma forma de inserir os sujeitos pobres no modelo produtivo. E num segundo momento, orientado pela adaptação a uma política mercadológica de trabalho. Assim, os indivíduos pobres passam a ser vistos como subsídios que poderiam inserir-se socialmente como mão de obra qualificada para manutenção de um desenvolvimento focado na produção e mercado consumidor do sistema capitalista (RAMOS; HEINSFELD, 2017).

Para Pacheco (2010), foi na tentativa de superar essa permanência que o Decreto $n^{\circ} 5.154 / 2004$ (BRASIL, 2004) propôs que essa modalidade de formação (EPT) deveria ser marcada pela "intervenção social crítica e qualificada, construindo mecanismos para favorecer a inclusão social e democratização dos bens sociais de uma sociedade" (BRASIL, 2009, p. 5). Em níveis conceituais, a proposição desse decreto possibilitaria uma reorganização estrutural no foco da formação via EPT no Brasil. E é considerando essa perspectiva que entendemos que a problematização dos conceitos de trabalho e política é importante na reflexão sobre a formação e educação dos sujeitos no contexto da EPT.

Abrangemos que essas duas categorias supracitadas, quando se pensa a História como disciplina escolar na EPT, possibilitam ampliar as extensões formativas por incidirem em formulações interpretativas sobre diversas dimensões da sociedade pelo viés histórico. Assim, quando ponderamos sobre a educação histórica e a disposição das categorias trabalho e política no contexto da EPT, entendemos que dilatam nossa configuração formativa no espaço das Ciências Humanas em uma Base que foi modelada seguindo premissas que priorizam o mercado, e não o mundo do trabalho e que, além disso, aponta a formação cidadã de maneira pouco objetiva, beirando inferências genéricas.

Consequentemente, sugerimos que nas categorias trabalho e política há indícios de focos para pensarmos uma tensão na BNCC. Afinal, entendemos que a discussão, estudo e aprofundamento nessas categorias no contexto da EPT podem permitir uma prática docente voltada para uma formação focalizada em dimensões mais integrais da disciplina de História. Entretanto, inferimos que tal prática não se efetiva pela proposição das categorias no currículo formal. 
É preciso que a atuação do docente esteja voltada para uma prática mais próxima da perspectiva do trabalho como princípio educativo e da atuação política no mundo.

Considerando o exposto, apresentaremos a seguir uma discussão sobre as categorias trabalho e política na BNCC, abrangendo suas propostas e inferências na formação segundo a Base. Assinalamos que seguiremos uma perspectiva qualitativa de análise, tomando a $\mathrm{BNCC}$ como nossa fonte primária de estudo.

\section{Trabalho, política e "História” na BNCC: que categorias são essas?}

Segundo documento homologado pela Portaria $n^{\circ}$ 1.570/2017 (BRASIL, 2017a), compreende-se que a BNCC é:

[...] um documento de caráter normativo que define o conjunto orgânico e progressivo de aprendizagens essenciais que todos os alunos devem desenvolver ao longo das etapas e modalidades da Educação Básica, de modo a que tenham assegurados seus direitos de aprendizagem e desenvolvimento, em conformidade com o que preceitua o Plano Nacional de Educação (PNE) (BRASIL, 2017b, p. 7).

Contudo, para Cury, Reis e Zanardi (2018), a BNCC tem caráter curricular. Para os autores, é preciso considerar que há na Base um ordenamento educacional que formula princípios constituidores do campo de estudos do Currículo, algo que a BNCC tenta evitar, pois é evidente que o documento "se constitui em um projeto normativo que estabelece um documento prescritivo de competências, habilidades, conteúdos, ou como preferem denominar, direitos de aprendizagem" (CURY; REIS; ZANARDI, 2018, p. 65, grifos nossos).

Outra questão pertinente para Cury, Reis e Zanardi (2018) é a contextualização da BNCC como campo de disputa de projetos sociais. Afinal, houve uma discussão objetiva na constituição da Base que evidenciava uma disputa pelo que seria a natureza dos objetos de conhecimento. Considerando esses elementos, afirmam que "desvelar a BNCC se constitui em obrigação dos educadores para a compreensão dos projetos que se colocam em disputa na sociedade e no interior da escola" (CURY; REIS; ZANARDI, 2018, p. 103). 
Portanto, compreendemos que não podemos naturalizar a construção dos objetos, categorias, conteúdo e princípios norteadores da BNCC. Por outro lado, é preciso questionar, criticar e historicizar sua construção, pois, como considera Cury, Reis e Zanardi (2018), ela não é um documento neutro sobre os princípios norteadores da formação das crianças e jovens do Brasil, e, nesse sentido, é preciso "colocar em destaque questões críticas sobre conteúdo, coerência e controle do currículo por organismos governamentais" (CURY; REIS; ZANARDI, 2018, p. 103). Considerando essa argumentação, nós problematizamos qual a conceituação de trabalho e política na BNCC como norteadores na formação dos jovens no contexto da EPT.

Inicialmente, é preciso considerar que a BNCC está estruturada em "Competências Gerais da Educação Básica", que compreendem etapas como Educação Infantil, Ensino Fundamental e Ensino Médio. A EPT insere-se no Ensino Médio e, especificamente, o Ensino Médio está organizado em quatro áreas do conhecimento, conforme determina a Lei de Diretrizes e Bases (LDB), sendo elas: Linguagens e suas Tecnologias, Matemática e suas Tecnologias, Ciências da Natureza e suas Tecnologias e Ciências Humanas e suas Tecnologias (BRASIL, 2017b, p. 32-33). Na BNCC, entende-se que cada área do conhecimento deve explicitar seu papel na formação integral dos estudantes do Ensino Médio. Ainda segundo a Base, ela "destaca particularidades no que concerne ao tratamento de seus objetos de conhecimento, considerando as características do alunado, as aprendizagens promovidas no Ensino Fundamental e as especificidades e demandas dessa etapa da escolarização" (BRASIL, 2017b, p. 33).

A História pertence à área de Ciências Humanas e suas Tecnologias, porém, no item 5.4 da BNCC, temos "A área de Ciências Humanas e Sociais Aplicadas (CHSA)", integrada por Filosofia, Geografia, História e Sociologia. Considerando especificamente a disciplina de História, Santos (2014) argumenta que o ensino e a aprendizagem em História precisam ser tomados como elementos pertencentes à educação e à sociedade contemporânea. Deste modo, é preciso demarcar, como assinalam Monteiro (2007) e Bittencourt (2004), que a História como disciplina escolar tem importância social particular na formação das pessoas e, acrescentamos, que isso deve ser considerado mesmo que a BNCC não esteja construída prevendo tal particularidade.

Sobre o Ensino Médio, a BNCC descreve que "é o período de ampliar e aprofundar as aprendizagens que foram desenvolvidas no Ensino Fundamental, sendo seu eixo orientador uma Educação Ética (BRASIL, 2017b, p. 547). Essa Educação Ética seria uma formação de juízo sobre a conduta humana, elemento considerado pela Base como necessário à vivência em sociedade. 
Essa proposta "tem como fundamento a compreensão e o reconhecimento das diferenças, o respeito aos direitos humanos e à interculturalidade, e o combate aos preconceitos" (BRASIL, 2017b, p. 547).

Considerando tal apontamento da Base, é válido assinalar que, para esse tipo de formação ética, a disciplina de História tem caráter estrutural. Afinal, como afirma Fonseca, Borges e Silva Júnior (2007), a História como disciplina escolar tem o potencial de ampliar os estudos sobre as diversas problemáticas contemporâneas, pois, ela, como campo de conhecimento, consegue situar distintas temporalidades, e isso acaba servindo como arcabouço para reflexões sobre as possibilidades, necessidades e mudanças histórica e socialmente elaboradas (FONSECA; BORGES; SILVA JÚNIOR, 2007).

Autoras como Fonseca (2003) e Silva e Fonseca (2007) já trataram sobre como na História da Educação escolar do Brasil a disciplina de História teve moldada em suas propostas inúmeras subjetividades sobre o objetivo escolar de como formar os indivíduos. As autoras assumem a tese de que a disciplina de História constantemente trazia em suas bases objetivos e funções específicos, e esses quase sempre se determinam por desígnios políticos, econômicos e até mesmo religiosos. Portanto, as autoras admitem que a disciplina de História vem historicamente atrelada, de alguma maneira, à formação de valores nos indivíduos.

Portanto, a partir do exposto, entendemos que os elementos tanto epistêmicos quanto axiológicos tornam a História uma disciplina-base na formação intelectual e ética dos estudantes na Educação básica. Ainda, como argumentam Santos e Arruda (2016), aprender História é fruto do trabalho intelectual humano; pensar historicamente não é algo inato, opostamente, é algo aprendido, desenvolvido e que precisa ser exercitado (SANTOS; ARRUDA, 2016).

Assim sendo, destacamos que a disciplina de História é pujante no que tange a formação dos jovens no Ensino Médio, afinal, ela admite a interpretação do mundo presente baseada em evidências do passado, oportunizando a aproximação de uma compreensão da realidade considerando a construção histórica da sociedade, das instituições, dos valores sociais, estéticos e culturais, dos sujeitos, da memória. Ou, como apontado por Santos (2014)

O estudo da História nos permite compreender que nada no mundo social é natural, algo nenhum é fenômeno imutável, os acontecimentos sociais e naturais estão num movimento de intensa mudança, tendo em vista que o ensino da História nos permite perceber essa oscilação que é o mundo humano, construído no tempo, de forma a não aceitar verdades postas, absolutas e inquestionáveis (SANTOS, 2014, p. 62). 
Além disso, a BNCC pondera que:

\begin{abstract}
No Ensino Médio, a ampliação e o aprofundamento dessas questões são possíveis porque, na passagem do Ensino Fundamental para o Ensino Médio, ocorre não somente uma ampliação significativa na capacidade cognitiva dos jovens, como também de seu repertório conceitual e de sua capacidade de articular informações e conhecimentos. O desenvolvimento das capacidades de observação, memória e abstração permite percepções mais acuradas da realidade e raciocínios mais complexos - com base em um número maior de variáveis -, além de um domínio maior sobre diferentes linguagens, o que favorece os processos de simbolização e de abstração (BRASIL, 2017b, p. 547).
\end{abstract}

Por ora, é importante admitir que a BNCC não infere uma existência objetiva para a disciplina de História, ou como afirma Peres (2017), no que tange às questões relativas à reformulação dos currículos, a História deixou de ser obrigatória. Além disso, sugere a autora que as Ciências Humanas se tornaram um campo do conhecimento que "vai perdendo a importância que possui, visto que geralmente não fornecem ao sistema capitalista 'produtos ou serviços' que atendam a seus interesses" (PERES, 2017, p. 7). Considerar a argumentação de Peres (2017) é importante, afinal, este texto problematiza a disciplina de História, mas reconhece a fragilidade imposta pela Base à disciplina.

Adiante na BNCC, após buscar justificar e legitimar o princípio "ético" da formação no Ensino Médio mediado pelas CHSA, a Base apresenta que a área:

está organizada de modo a tematizar e problematizar, no Ensino Médio, algumas categorias da área que são fundamentais à formação dos estudantes, sendo elas: tempo e espaço; territórios e fronteiras; indivíduo, natureza, sociedade, cultura e ética; e política e trabalho (BRASIL, 2017b, p. 549, grifos nossos).

Segundo a BNCC, essas categorias são fundantes para a investigação e a aprendizagem, sendo preciso distinguir que tais categorias não se confundem com temas ou proposta de conteúdo. Assim, como categorias, trabalho e políticas estão dispostas na BNCC como inferências de compreensão das ideias, dos fenômenos e dos processos políticos, sociais, econômicos e culturais. E no Ensino Médio, elas são explicitadas considerando a capacidade de abstração e 
simbolização dos estudantes (BRASIL, 2017b). Segundo a BNCC, as categorias referem-se a fundamentos da formação, sendo essenciais para compreensão, "investigação e aprendizagem" dos estudantes (BRASIL, 2017b, p. 550).

De maneira generalista, podemos considerar que categorias servem como conceitos genéricos que podem expressar diferentes relações possíveis que se estabelecem entre ideias e/ou fatos. Segundo a "The Stanford Encyclopedia of Philosophy"2 (THOMASSON, 2019), existe uma tradição filosófica baseada em princípios aristotélicos que conceitua categoria como algo que serve para designar alguma coisa, um tipo de inventário de tudo o que existe e que responderia às questões básicas da metafísica.

Todavia, é preciso ponderar que a conceituação de categoria historicamente apresenta variações, questionamentos e atualizações. A exemplo, tem-se a noção cética que infere que não temos capacidade de formulações gerais que deem conta de criar um sistema unívoco sobre a realidade. Nesse sentido, o que há é um sistema de categorias que permite ao humano uma base para conhecer determinados objetos, e esse sistema seria o que nos permite elucidar as categorias de nossa conceitualidade (THOMASSON, 2019).

Para Thomasson (2019), é com Kant que se cria uma mudança para uma abordagem conceitualista, traçando que as categorias são a priori necessárias para qualquer possível cognição sobre objetos. O autor afirma que:

Depois de Kant, tem sido comum abordar o projeto de categorias em um espírito neutro que Brian Carr $(1987,7)$ chama de "descritivismo categorial", que descreve a estrutura categorial que o mundo teria de acordo com nosso pensamento, experiência ou linguagem. Embora se abstenha de assumir compromissos sobre se essas categorias estão ou não ocupadas ou são onticamente fundamentais, Edmund Husserl aborda as categorias dessa maneira, pois ele começa apresentando categorias de significados, o que pode ser usado para desenhar categorias ontológicas (categorias de objetos passíveis de significados) como correlatos das categorias de significado, sem se preocupar com qualquer questão empírica sobre se realmente existem ou não objetos das várias categorias ontológicas discernidas (THOMASSON, 2019, tradução nossa). 
Entendemos, em consonância com o autor, que é preciso considerar que vários sistemas de categorias têm potencial explicativo. Contudo, os mesmos enfrentam uma variedade de dificuldades. Nesse sentido, é preciso considerar a mudança histórica e intelectual nas tentativas de oferecer sistemas completos de categorias. Afinal, essas são "[...] particulares, especialmente entre as [...] considerações conceituais ou linguísticas” (THOMASSON, 2019, tradução nossa).

Mesmo considerando a argumentação de Thomasson (2019), apresentamos a proposta de Durkheim (1996). Esse autor indica que é preciso reconhecer a origem social das categorias, e essas se traduzem em sentidos produzidos com alguma coletividade. Para Durkheim (1996), mesmo que cada indivíduo expresse e carregue algumas marcas, os conceitos elaborados que permitem a ele discernir sobre diferentes objetos constituem modos como as sociedades e os grupos sociais, em certas épocas, representam as diferentes coisas, entre elas a natureza, os sentimentos, os objetos, as relações e as ideias. Nesse sentido, as categorias podem ser conceitos que expressam coisas e sentidos socialmente elaborados.

Assim sendo, compreendemos que o esforço de Durkheim (1996) é indicar que existe uma elaboração sobre a realidade e a vida humana que é construída social e historicamente, e essa construção compõe o que poderíamos chamar de visão de mundo, oferecendo aos indivíduos formas de pensar, lidar, compreender, elaborar, conhecer e estabelecer relações entre os objetos exteriores com as ideias e abstrações interiores (cognição), e esse processo de conhecimento acaba por ser expressado a partir de conceitos e símbolos, incluindo aqui as categorias de conhecimento. Logo, a BNCC é coerente em afirmar que categorias não são conteúdos, mas elementos de problematização para os conteúdos. Portanto, entendemos que trabalho e política são categorias que permitem à área de CHSA construir (mesmo que com alguma parcialidade) explicações, interpretações e análise sobre o mundo humano. Desse modo, tais categorias podem oferecer fundamentos didáticos e formativos aos estudantes da EPT quando tratados na disciplina de História.

Dito isso, adentremos em como a BNCC explora a categoria trabalho e em seguida a política.

A categoria trabalho [...] comporta diferentes dimensões - filosófica, econômica, sociológica ou histórica: como virtude; como forma de produzir riqueza, de dominar e de transformar a natureza; como mercadoria; ou como forma de alienação. Ainda podemos falar do trabalho como categoria pensada por diferentes autores: trabalho como valor (Karl Marx); como racionalidade capitalista (Max Weber); ou como elemento de interação do indivíduo na sociedade em suas dimensões, tanto corporativa 
como de integração social (Émile Durkheim). Seja qual for o caminho ou os caminhos escolhidos para tratar do tema, é importante destacar a relação sujeito/trabalho e toda a sua rede de relações sociais.

Atualmente, as transformações na sociedade são grandes, especialmente em razão do uso de novas tecnologias. Observamos transformações nas formas de participação dos trabalhadores nos diversos setores da produção, a precarização das relações de trabalho, as oscilações de taxas de emprego e desemprego, o uso do trabalho intermitente, a pulverização dos locais de trabalho e o aumento global da concentração de renda e da desigualdade social. Diante desse cenário, a experiência do trabalho na contemporaneidade impõe novos desafios e problematizações formuladas no campo das Ciências Humanas, incluindo os impactos das inovações tecnológicas nas relações de produção e de trabalho (BRASIL, 2017b, p. 556).

Percebemos que no documento não há uma preocupação em historicizar o trabalho, ele está apresentado em uma vertente mais próxima de uma abordagem sociológica. Contudo, é importante ressaltar que a historicização da categoria pode ampliar a abordagem no sentido de pensar suas mudanças ao longo do tempo, e não atribuir ao trabalho a ideia direcionada ao "uso de novas tecnologias". Esse reducionismo temporal desagrega complexidade e reduz a importância da abordagem histórica. E isso restringe a categoria trabalho a uma analogia rasa, à ideia de emprego e desigualdade na sociedade capitalista, elemento evidenciado no segundo parágrafo do documento descrito acima.

Para apresentarmos uma ampliação da categoria, consideraremos alguma possibilidade da abordagem pela História. Kalina Vanderlei Silva e Maciel Henrique Silva (2009) afirmam que "em sua definição mais comum, trabalho é toda ação de transformação da matéria natural em cultura, ou seja, toda transformação executada por ação humana" (SILVA, K.; SILVA, M., 2009, p. 401). Ao partir dessa elaboração generalista, considera-se que toda sociedade humana trabalha e, em sua diversidade contextual, os humanos criam e produzem sua existência. Ideia encontrada de maneira esvaziada no documento da BNCC, afinal, a dimensão da cultura é fundamental para pensar os resultados materiais e imateriais do trabalho, e essa abordagem fica diminuída na Base. Nossa hipótese permeia a desobrigação da disciplina de História como fato.

Segundo Lukács (2013), o modo de relacionar-se com a natureza em que se produz permanentemente algo novo tem como princípio o trabalho, mas não apenas esse elemento produtivo próximo a uma leitura econômica, mas também a sociabilidade e a intelectualidade humana, ambos os elementos pertencem a uma categoria fundante, o trabalho. Portanto, essa categoria carrega em si os 
elementos ontológicos do ser social. Contudo, como afirma Lukács (2013), é preciso ater-se que "nenhuma categoria pode ser adequadamente compreendida se for considerada isoladamente" (LUKÁCS, 2013, p. 41).

Sobre o trabalho, o autor afirma que "a essência do trabalho humano consiste no fato de que, em primeiro lugar, ele nasce em meio à luta pela existência e, em segundo lugar, todos os seus estágios são produtos de sua autoatividade" (LUKÁCS, 2013, p. 43). Segundo Hostins, Rochadel e Melo (2019), Lukács (2013) aproveita a definição de Marx (1983) sobre trabalho, cuja ontologia distingue trabalho abstrato de trabalho fundante. Sendo que:

O primeiro compreende as atividades assalariadas, próprias do sistema capitalista, em que se define um valor de troca de serviços por dinheiro; o segundo representa a atividade por meio da qual o homem transforma a natureza e a si mesmo como pressuposto essencial de sua existência no mundo (HOSTINS; ROCHADEL; MELO, 2019, p. 176).

Considerar as argumentações dos autores é demasiadamente importante, pois essa distinção analítica, temporal e histórica que é a forma do trabalho no sistema capitalista, muitas vezes entendido como emprego, não deve ser confundida com a perspectiva marxiana do trabalho como essencial na fundação do ser humano como ser social, o primata bípede torna-se um ser social através da execução do trabalho. Ou como adverte Lukács (2013):

Somente o trabalho tem, como sua essência ontológica, um claro caráter de transição: ele é, essencialmente, uma inter-relação entre homem (sociedade) e natureza, tanto inorgânica (ferramenta, matéria-prima, objeto do trabalho etc.) como orgânica, inter-relação que pode figurar em pontos determinados da cadeia a que nos referimos, mas antes de tudo assinala a transição, no homem que trabalha, do ser meramente biológico ao ser social (LUKÁCS, 2013, p. 44).

Neste momento, é válido ressaltar um apontamento feito por Marcuse (1978), ao estudar a Filosofia do Espírito em Hegel. Marcuse (1978) entende que: 
A linguagem, então, possibilita ao indivíduo a tomada de uma posição consciente contra seus semelhantes, e a afirmação de suas necessidades e desejos contra as necessidades e os desejos dos outros indivíduos. Os antagonismos que daí resultam são integrados por meio do processo do trabalho, que se torna, portanto, a força decisiva para o desenvolvimento da cultura (MARCUSE, 1978, p. 81).

Aqui importa salientar que o autor está abordando o pensamento de Hegel e, nesse sentido, o trabalho se apresenta como uma síntese, tornando-se uma força criativa, que nesse caso produz a cultura, uma artificialidade humana. Ressalta-se que o trabalho também é responsável por vários tipos de integração e condiciona outras formas subsequentes, como a família, a sociedade civil e o Estado. A natureza não é negligenciada nessa dimensão dialética, incluindo que ela se instala na história do homem nesse processo. Assim, a história passa a ser essencialmente a história humana. Ou seja, entendemos que é pelo trabalho que o homem artificializa um mundo e reconstrói uma síntese humana de existência, de um ser que é social e cultural.

Para Marcuse (1978), o salto de Marx foi indagar-se sobre o sentido que o trabalho tem com referência ao desenvolvimento do homem/humano. Assim, a elaboração começa a perpassar a ideia de que o trabalho é uma espécie de atividade existencial do próprio ser humano. Trata-se, portanto, não apenas de um meio de conservação da sobrevivência vital, mas um meio de desenvolvimento de uma natureza universal. Em síntese, uma premissa de compreensão é importante: o ser humano é o resultado do seu trabalho. Ou seja, há uma autocriação, mas essa não se esgota no sujeito que trabalha, o produto se perpetua no mundo como experiência acumulada para a própria História da humanidade.

Além disso, é necessário ressaltar que "Marx achava que a filosofia de Hegel fôra a mais desenvolvida e compreensiva apresentação dos princípios burgueses" (MARCUSE, 1978, p. 240). Essa distinção se faz necessária para delimitar que há inúmeras diferenças entre os autores Hegel e Marx. Uma apontada pelo autor é que em Marx os conceitos filosóficos são categorias econômicas e sociais, enquanto que as categorias econômicas e sociais de Hegel são conceitos filosóficos. Isso é importante de delimitar, pois, segundo Marcuse (1978), a teoria marxista "tem um fundamento material diferente, do mesmo modo que a nova teoria tem uma nova estrutura e um novo arcabouço conceitual que não podem ser derivados de teorias anteriores" (MARCUSE, 1978, p. 439).

Essas considerações são importantes de serem feitas, pois entendemos que a categoria trabalho apresentada na BNCC ignora elementos mais complexos do trabalho, do ser social e da cultura numa possibilidade histórica 
de abordagem e, quando problematizamos o trabalho no contexto da EPT, esses elementos ontológicos são importantes de serem pensados, principalmente considerando a perspectiva do trabalho como princípio educativo para um Ensino Médio Integrado, e entendemos que a disciplina de História tem profundidade para abordagem do tema de maneira formativa e integral para os jovens no Ensino Médio na EPT.

Sobre a categoria política, a BNCC indica que:

A política ocupa posição de centralidade nas Ciências Humanas. As discussões em torno do bem comum, dos regimes políticos e das formas de organização em sociedade, as lógicas de poder estabelecidas em diferentes grupos, a micropolítica, as teorias em torno do Estado e suas estratégias de legitimação e a tecnologia interferindo nas formas de organização da sociedade são alguns dos temas que estimulam a produção de saberes nessa área.

A política está na origem do pensamento filosófico. Na Grécia Antiga, o exercício da argumentação e a discussão sobre os destinos das cidades e suas leis estimularam a retórica e a abstração como práticas necessárias para o debate em torno do bem comum. Esse exercício permitiu ao cidadão da pólis compreender a política como produção humana capaz de favorecer as relações entre pessoas e povos e, ao mesmo tempo, desenvolver a crítica a mecanismos políticos como a demagogia e a manipulação do interesse público. A política, em sua origem grega, foi o instrumento utilizado para combater os autoritarismos, as tiranias, os terrores, as violências e as múltiplas formas de destruição da vida pública.

No mundo contemporâneo, essas questões observadas tanto em escala local como global ganham maior visibilidade na Geopolítica, pois ela enuncia os conflitos planetários entre pessoas, grupos, países e blocos transnacionais, desafio importante de ser conhecido e analisado pelos estudantes.

As discussões sobre formas de organização do Estado, de governo e do poder são temáticas enunciadas no Ensino Fundamental e aprofundadas no Ensino Médio, especialmente em sua dimensão formal e como sistemas jurídicos complexos. Essas temáticas apresentadas de forma ampla na BNCC fornecem alguns elementos capazes de agregar diversos temas de ordem econômica, social, política, cultural e ambiental e permitem, sobretudo, a discussão dos conceitos veiculados por diferentes sociedades e culturas (BRASIL, 2017b, p. 556).

Diferente da categoria trabalho, a política é apresenta de maneira mais aberta na BNCC. Um ponto a ser ressaltado é que a apresentação dela tende a uma historização, mas ainda focada em um eixo eurocêntrico de entendimento. 
É perceptível que a BNCC ressalta a categoria política em torno de uma conceituação que se alinha à ideia de debate, discussão e elaboração retórica. No entanto, é importante ressaltar, como indica Sartori (1992), que a política é um fazer humano, e não apenas um conceito teórico, mas algo exercido, praticado, que não se reduz a uma abstração genérica e se produz em relações.

Para Bobbio, Matteucci e Pasquino (1998), a política desde seu significado clássico expressava tudo o que se referia à cidade, civil, público, e até mesmo ao que é social. Na modernidade, o termo passa a indicar atividade ou conjunto de atividades que, de alguma maneira, tem como referência o Estado. Nesses sentidos, a política tende a ser compreendida como "sujeito" quando é incluída como atos de ordenar ou proibir, exercer domínio territorial, legislar, tirar ou transferir recursos. Mas há o entendimento da política como “objeto", trata-se dela no entendimento de conquista, manutenção, defesa, ampliação, robustecimento, derrubada ou destruição do poder estatal (BOBBIO; MATTEUCCI; PASQUINO, 1998, p. 954). Essa definição, para o autor, de sujeito e objeto, é importante de ser enfatizada quando se pensa na política como elemento de reflexão sobre a atividade política, equivalendo, por isso, a "elementos de filosofia política". Destacamos que a BNCC incorpora esses elementos interpretativos. A exemplo, na afirmação: "a política [...] instrumento utilizado [...]" (BRASIL, 2017b, p. 556), aqui ela é objeto ou no caso a política “[...] enuncia os conflitos planetários [...]" (BRASIL, 2017b, p. 556) aqui, permite-se ser pensada como sujeito.

Contudo, para Miguel (2018), a política "é um conceito complexo, sobre o qual o único consenso existente é que deve incluir, de alguma maneira, a ideia de disputa pelo poder" (MIGUEL, 2018). Sobre o poder, a BNCC anuncia-o como temática, elemento importante de ser ressaltado, mesmo que na Base ele esteja colocado como artifício secundário. Por isso, é importante atermos ao apontamento de Miguel (2018):

Se o conceito é reduzido ao mínimo, a política se torna desprovida de especificidade e coextensiva a todo o social, pois se sabe que as relações de poder perpassam toda a teia de relações humanas. No caminho inverso, a maior parte da ciência política busca estreitar a abrangência do conceito, limitando-o às dimensões estritas da política institucional (partidos, governos, parlamentos, eleições; também a diplomacia, como política externa). Com isso, porém, não apreende os conflitos relativos à politização de fenômenos sociais que escapam da política institucional ou do campo político propriamente dito. Não é capaz, portanto, de analisar fenômenos da dominação social que passam pelo impedimento à expressão de determinadas reivindicações ou reclamos nas arenas aceitas como políticas (MIGUEL, 2018). 
Considerando a argumentação, é salutar compreender a política como processo, sendo esse o elemento pelo qual se obtém acesso ao exercício do poder nas dimensões da organização da vida coletiva numa sociedade. Assim sendo, Miguel (2018) compreende que a política é uma forma de reificação de um processo histórico. Portanto, sua compreensão é dotada de sentido apenas à luz de seu percurso histórico e das relações sociais em que se introduz. Além disso, importa afirmar que, socialmente, a humanidade geralmente encontra maneiras de organizar suas vidas em coletividade. Logo, a política acaba por ser também uma prática presente em inúmeras sociedades encontradas no tempo histórico.

Para Miguel (2018), é preciso lançar mão das inúmeras disputas que ocorrem no tecido social e na ordem vigente de dominação. Nesse sentido, afirma o autor que a definição do que é política consiste na disputa política elementar, ou seja, historicamente é perceptível que, por exemplo, o movimento operário politizou as relações de trabalho, o movimento feminista politizou a esfera doméstica, e o movimento ambientalista politizou a relação da humanidade com o meio natural que a cerca. Portanto, é fundamentalmente necessário afirmar que "a compreensão de que as relações de trabalho, a família e a exploração da natureza são questões políticas continua a ter que ser sustentada todos os dias" (MIGUEL, 2018). De tal maneira, "a política é percebida como a prática que expressa as contradições presentes na sociedade e a arena em que se encontram as soluções, sempre provisórias, para elas" (MIGUEL, 2018).

Em síntese, afirma o autor que é mais frutífero compreender a política como um conjunto de relações e de práticas sociais historicamente determinadas, cuja abrangência é produto igualmente das lutas sociais. Nesse sentido, sugere que:

A compreensão aprofundada da política exige tanto superar a marola das disputas do momento, conectando-as com os conflitos sociais mais profundos, quanto entender sua relação com os interesses materiais - a divisão do trabalho, o controle da riqueza, a distribuição dos frutos da cooperação social, o acesso aos diferentes espaços sociais (MIGUEL, 2018).

Logo, essa apresentação suscita a base teórica de que é importante enfatizar que os conflitos na sociedade que imprimem a constância do poder não podem ser abrangidos sem sua relação com a base material temporalmente determinadas. Algo não explicitado ou proposto pela BNCC.

Para Gramsci (2007): 
O político em ato é um criador, um suscitador, mas não cria a partir do nada nem se move na vazia agitação de seus desejos e sonhos. Toma por base a realidade efetiva: mas o que é esta realidade efetiva? Será algo estático e imóvel, ou, ao contrário, uma relação de forças em contínuo movimento e mudança de equilíbrio? Aplicar a vontade à criação de um novo equilíbrio das forças realmente existente e atuantes, baseando-se naquela determinada força que se considera progressiva, fortalecendo-a para fazê-la triunfar, significa continuar movendo-se no terreno da realidade efetiva, mas para dominá-la e superá-la (ou contribuir para isso). Portanto, o 'dever ser' é algo concreto, ou melhor, somente ele é história em ato e filosofia em ato, somente ele é política (GRAMSCI, 2007, p. 35, grifos nossos).

Segundo Coutinho (2011), Gramsci (2007) na "realidade efetiva" demonstra a retomada em Maquiavel (2012) que afirma ser sua

[...] intenção escrever algo de útil para quem por tal se interesse, pareceu-me mais conveniente ir em busca da verdade extraída dos fatos e não à imaginação dos mesmos, pois muitos conceberam repúblicas e principados jamais vistos ou conhecidos como tendo realmente existido (MAQUIAVEL, 2012, p. 133).

Mas para Coutinho (2011), Gramsci (2007) elabora que "a relação de força" é elevada a uma determinação da própria "realidade efetiva". Nesse sentido, afirma Coutinho (2011):

Estamos diante de uma das mais importantes passagens dos Cadernos, na qual Gramsci se propõe desenvolver uma de suas principais contribuições ao que ele chama reiteradas vezes de "ciência política da filosofia da práxis", ou seja, precisamente sua proposta de "análise das situações" (COUTINHO, 2011, p. 128).

Assim, podemos inferir que é preciso pensar em uma perspectiva que considere uma maior dimensão dialética da categoria política. Não negando sua contribuição teórica, reflexiva ou retórica como parece insistir a BNCC, todavia, é necessário compreendê-la em proposições que envolvam as diferentes perspectivas processuais e de relação humana frente ao poder no percurso 
temporal do ser humano, não caindo em um abismo que separa idealmente a teoria da prática historicamente construídas, mas assegurar análises de base material e histórica, entendendo que a disputa de poder se dá para além do Estado, e que as relações e reações a esse poder envolvem ampla conjuntura social, que vai desde os indivíduos comuns no dia a dia até as instituições e suas abstrações. E nesse sentido, a manutenção da disciplina de História torna-se imprescindível para a formação dos jovens na EPT.

Considerando o exposto, apontamos que mesmo que a Lei $\mathrm{n}^{\circ} 13.415$, de 16 de fevereiro de 2017 (BRASIL, 2017c), não garanta obrigatoriedade da disciplina de História, ressaltamos que as unidades de Ensino, seus currículos e a atividade docente têm oportunidades de resistência para manutenção da disciplina. Afinal, como aponta Moreira e Silva (2013), Macedo (2006), Apple (2008), entre outros autores do campo de estudo do Currículo, não podemos negligenciar as diversas relações de poder que perpassam as determinações curriculares, incluindo com isso as resistências no cotidiano escolar junto ao currículo real/praticado. Há uma dialética complexa entre o currículo documental formal e o exercício, vivido e praticado.

\section{Considerações}

Este artigo pretende ser inicial, afinal, são apontamentos que precisam de mais complexidades da prática escolar para ampliar suas mediações e possibilidades. Ainda é preciso considerar que a Resolução $\mathrm{n}^{\circ} 4$, de 17 de dezembro de 2018, no seu capítulo V, afirma: "A adequação dos currículos à BNCC-EM deve estar concluída até início do ano letivo de 2020, para a completa implantação no ano de 2022" (BRASIL, 2018). Como apresentamos inicialmente, há no Brasil uma problematização histórica em torno da EPT, a fim de criar condições de superação de Educação Profissional reducionista de caráter tecnicista. A instituição e expansão da rede EPT na primeira década dos anos 2000 ambicionava a criação de currículos e estruturas educacionais mais integradas e que pudessem consolidar formação Profissional e Tecnológica de maneira mais omnilateral.

Todavia, o contexto da segunda década dos anos 2000 é marcado por inúmeras disputas em torno de uma Base Nacional para Educação e, nesta conjuntura, a disciplina de História sofre ataques, o que redimensiona as nossas possibilidades de atuação. Esses eventos impõem situações limitadoras à disciplina de História e às Ciências Humanas no contexto da EPT, que 
apresenta maiores percalços para uma formação integral dos jovens nesse contexto formativo. Nesse sentido, importa atentarmos ao dissolvimento do campo da História dentro das "Ciências Humanas", evidenciando um amplo empobrecimento da conceituação das categorias que, por sua especificidade temporal, demanda análise dentro da historicidade e construção não naturalizada dos eventos sociais que são construídos pelos humanos através de suas histórias no tempo.

Ainda como foi discutido neste texto, a disciplina de História tem caráter e especificidades que precisam ser consideradas na formação dos jovens no Ensino Médio, a História como disciplina autônoma tem abordagens, estruturas e meios de problematizações acerca da temporalidade e formação humana que a distinguem de outras áreas do conhecimento, mesmo estando ela acoplada num denominador "macrocomum", as Ciências Humanas. De tal forma, percebemos que as categorias trabalho e política podem ser estruturas importantes para reformulação de currículos mais sólidos do ponto de vista formativo na EPT. Todavia, caso as instituições e os docentes pretendam adotar a Base sem tensionamentos mais críticos, corre-se o risco de esvaziamento crítico na formação em Ciência Humanas, perdendo o potencial integrado do Ensino Médio no contexto da EPT e esvaziando a formação ética pretendida pela Base. Aparentemente, essas duas categorias podem ser elementos tensionadores na EPT quando problematizamos a disciplina de História, mas é preciso recorrer a estratégias mais críticas e profundas da abordagem histórica e processual das relações humanas no tempo de maneira que os jovens da EPT possam acessar mais elementos críticos na abordagem da disciplina. Ainda é preciso maior esforço para legitimar a disciplina (História) e sua importância formativa e, aparentemente, a BNCC que ora nos está disponível não atende a essa demanda.

\section{REFERÊNCIAS}

APPLE, Michael. Repensando ideologia e currículo. In: MOREIRA, Antônio Flávio Barbosa; SILVA, Tomaz Tadeu da (org.). Currículo, Cultura e Sociedade. 10. ed. São Paulo: Cortez, 2008. p. 39-58.

BENAKOUCHE, Rabah. A Transnacionalização do Capital. Rev. adm. empres., Rio de Janeiro, v. 20, n. 1, p. 79-90, jan./mar. 1980. Disponível em: https://www.scielo.br/pdf/ rae/v20n1/v20n1a06.pdf. Acesso em: 29 set. 2020. 
BITTENCOURT, Circe Maria Fernandes. Ensino de História: fundamentos e métodos. São Paulo: Cortez, 2004.

BOBBIO, Norberto; MATTEUCCI, Nicola; PASQUINO, Gianfranco. Dicionário de política. Tradução de Carmen C. Varriale et al.; João Ferreira (coord.). Tradução e Revisão Geral de João Ferreira e Luis Guerreiro Pinto Cacais. 11. ed. Brasília: Editora Universidade de Brasília, 1998. v. 1.

BRASIL. Presidência da República. Decreto $n^{\circ} 7.566$, de 23 de setembro de 1909. Crêa nas capitaes dos Estados da Republica Escolas de Aprendizes Artifices, para o ensino profissional primario e gratuito. Rio de Janeiro, RJ: Presidência da República, 23 set. 1909. Disponível em: https://www2.camara.leg.br/legin/fed/decret/1900-1909/decreto7566-23-setembro-1909-525411-publicacaooriginal-1-pe.html. Acesso em: 29 set. 2020.

BRASIL. Lei no 5.692, 11 de agosto de 1971. Lei de Diretrizes e Bases para o ensino de $1^{\circ}$ e $2^{\circ}$ graus. Diário Oficial da União: seção 1, Brasília, p. 6377, 12 ago. 1971. Disponível em: https:/www2.camara.leg.br/legin/fed/lei/1970-1979/lei-5692-11-agosto1971-357752-publicacaooriginal-1-pl.html. Acesso em: 24 nov. 2020.

BRASIL. Lei n 9.394, 20 de dezembro de 1996. Lei de Diretrizes e Bases da Educação Nacional. Diário Oficial da União: seção 1, Brasília, p. 27833, 23 dez. 1996. Disponível em: http://www.planalto.gov.br/ccivil_03/leis/19394.htm. Acesso em: 29 set. 2020.

BRASIL. Presidência da República. Decreto $n^{\circ} 5.154$ de 23 de julho de 2004. Regulamenta o $\S 2^{\circ}$ do art. 36 e os arts. 39 a 41 da Lei $n^{\circ} 9.394$, de 20 de dezembro de 1996, que estabelece as diretrizes e bases da educação nacional, e dá outras providências. Brasília, DF: Presidência da República, 2004. Disponível em: http://www.planalto.gov. br/ccivil_03/_ato2004-2006/2004/decreto/d5154.htm. Acesso em: 29 set. 2020.

BRASIL. Ministério da Educação. Criação da Rede Federal de Educação Profissional e Tecnológica. Centenário da Rede Federal de educação profissional e tecnológica. Brasília, DF: MEC, 23 set. 2009. p. 2-5. Disponível em: http://portal.mec.gov.br/setec/ arquivos/centenario/historico_educacao_profissional.pdf. Acesso em: 29 set. 2020.

BRASIL. Ministério da Educação. Portaria n ${ }^{\circ} 1.570,21$ de dezembro de 2017. Diário Oficial da União: seção 1, Brasília, p. 146, 21 dez. 2017a.

BRASIL. Base Nacional Comum Curricular (BNCC). Brasília, DF: MEC, $2017 \mathrm{~b}$. Disponível em: http://basenacionalcomum.mec.gov.br/a-base. Acesso em: 29 set. 2020.

BRASIL. Presidência da República. Lei $n^{\circ} 13.415,16$ de fevereiro de 2017. Altera as Leis $\mathrm{n}^{\circ}$ 9394, de 20 de dezembro de 1996, que estabelece as diretrizes e bases da Educação Nacional [...]; e institui a política de fomento à implementação de Escolas de Ensino Médio em tempo integral. Brasília, DF: Presidência da República, 2017c. Disponível em: http:/www.planalto.gov.br/ccivil_03/_Ato2015-2018/2017/Lei/L13415.htm. Acesso em: 29 set. 2020 . 
BRASIL. Ministério da Educação. Resolução nº 4, de 17 de dezembro de 2018. Institui a Base Nacional Comum Curricular na Etapa do Ensino Médio (BNCC-EM), como etapa final da Educação Básica, nos termos do artigo 35 da LDB, completando o conjunto constituído pela BNCC da Educação Infantil e do Ensino Fundamental, com base na Resolução CNE/CP n ${ }^{\circ}$ 2/2017, fundamentada no Parecer CNE/CP n ${ }^{\circ}$ 15/2017. Diário Oficial da União: seção 1, Brasília, DF, p. 120-122, 18 dez. 2018.

COUTINHO, Nelson. De Rousseau a Gramsci: Ensaios de teoria política. São Paulo: Boitempo, 2011.

CUNHA, Luiz Antônio. O ensino de ofícios manufatureiros em arsenais, asilos e liceus. Forum educacional, v. 3, n. 3, p. 3-47, jul./set. 1979. Disponível em: https:// bibliotecadigital.fgv.br/ojs/index.php/fe/article/view/60512. Acesso em: 29 set. 2020.

CUNHA, Luiz Antônio. O ensino de ofícios artesanais e manufatureiros no Brasil escravocrata. 2. ed. São Paulo: Editora UNESP; Brasília, DF: FLACSO, 2005.

CURY, Carlos Roberto Jamil; REIS, Magali; ZANARDI, Teodoro Adriano Costa. Base Nacional Comum Curricular: dilemas e perspectivas. São Paulo: Cortez, 2018.

DURKHEIM, Émile. As formas elementares da vida religiosa. São Paulo: Martins Fontes, 1996.

FONSECA, Selva Guimarães; BORGES, Vilmar José; SILVA JÚNIOR, Astrogildo Fernandes da. Ensinar Geografia e História: relações entre sujeitos, saberes e práticas. In: FONSECA, Selva Guimarães (org.). Currículos, saberes e culturas escolares. Campinas: Alínea, 2007. p. 31-59.

FONSECA, Thaís Nívia de Lima e. História \& Ensino de História. Belo Horizonte: Autêntica, 2003.

FRIGOTTO, Gaudêncio; CIAVATTA, Maria; RAMOS, Marise. A política de educação profissional no Governo Lula: um percurso histórico controvertido. Educação e Sociedade, Campinas, v. 26, n. 92, out. 2005. Disponível em: https:/www.scielo.br/ scielo.php?script=sci_arttext\&pid=S0101-73302005000300017. Acesso em: 27 set. 2020.

GRAMSCI, Antônio. Cadernos do Cárcere: Maquiavel. Notas sobre o Estado e a política. 3. ed. Rio de Janeiro: Civilização Brasileira, 2007. v. 3.

HOSTINS, Regina Célia Linhares; ROCHADEL, Olívia; MELO, Alessandra Giacomett. O conceito de trabalho em Lukács: implicações no campo da política educacional. Conjectura: Filos. Educ., Caxias do Sul, RS, v. 24, p. 174-190, 2019. Disponível em: http://ucs.br/etc/revistas/index.php/conjectura/article/download/6617/pdf. Acesso em: 20 set. 2020 .

LUKÁCS, György. Para uma ontologia do ser social II. São Paulo: Boitempo, 2013.

MACEDO, Elizabeth. Currículo: Política, Cultura e Poder. Currículo sem Fronteiras, [s. l.], v. 6, n. 2, p. 98-113, jul./dez. 2006. 
MANACORDA, Mario Alighiero. História da Educação: da Antiguidade aos nossos dias. 12. ed. São Paulo: Cortez, 2006.

MARCUSE, Herbert. Razão e revolução: Hegel e o advento da teoria social. 2.ed. São Paulo: Paz e Terra, 1978.

MAQUIAVEL, Nicolau. O Príncipe. Tradução de Leda Beck. São Paulo: Martin Claret, 2012. (Coleção a Obra Prima de Cada Autor, v. 2.).

MARX, Karl. O capital: crítica da economia política. São Paulo: Abril Cultural, 1983.

MIGUEL, Luis Felipe. Marx e a ciência política. Blog da Boitempo. São Paulo, 07 maio 2018. Disponível em: https://blogdaboitempo.com.br/2018/05/07/marx-e-a-cienciapolitica. Acesso em: 29 set. 2020.

MONTEIRO, Ana Maria. Professores de história: entre saberes e práticas. Rio de Janeiro: Mauad X, 2007.

MOREIRA, Antônio Flávio Barbosa; SILVA, Tomaz Tadeu da. Sociologia e teoria crítica do currículo: uma introdução. In: MOREIRA, Antônio Flávio Barbosa; SILVA, Tomaz Tadeu da (org.). Currículo, cultura e sociedade. 12. ed. São Paulo: Cortez, 2013. p. 7-31.

PACHECO, Eliezer. Os Institutos Federais: uma revolução na educação profissional e tecnológica. Natal: IFRN, 2010. Disponível em: http://portal.mec.gov.br/setec/arquivos/ pdf/insti_evolucao.pdf. Acesso em: 29 set. 2020.

PERES, Maria Gisele. O Ensino de História na Educação Técnica e Profissional: desafios e perspectivas. In: SEMINÁRIO INTERNACIONAL DE HISTÓRIA DO PRESENTE, 3., 2017, Florianópolis. Anais [...]. Florianópolis, SC: UDESC, 2017. p. 1-10. Disponível em: http://eventos.udesc.br/ocs/index.php/STPII/IIISIHTP/paper/viewFile/654/410. Acesso em: 29 set. 2020.

RAMOS, Flávia Regina Oliveira; HEINSFELD, Bruna Damiana de Sá Sólon. Reforma do Ensino Médio de 2017 (lei no 13.415/2017): um estímulo à visão utilitarista do conhecimento. In: EDUCERE, 13., 2017, Curitiba. Anais [...]. Curitiba: PUCPR, 2017. p. 18284-18300. Disponível em: https://educere.bruc.com.br/arquivo/ pdf2017/24107_11975.pdf. Acesso em: 29 set. 2020.

SALES, Paula Elizabeth Nogueira; OLIVEIRA, Maria Auxiliadora Monteiro. Políticas de educação profissional no Brasil: trajetórias, impasses e perspectivas. In: CARVALHO, Maria Lucia Mendes de (org.). Cultura, saberes e práticas: memórias e história da educação profissional. São Paulo: Centro Paula Souza, 2011. p. 165-184.

SANTOS, Bergston Luan. Interpretando "Mundos": Jogos Digitais \& Aprendizagem Histórica. 2014. 193 f. Dissertação (Mestrado em Ciências Humanas) - Universidade Federal de Uberlândia, Uberlândia, 2014. Disponível em: https://repositorio.ufu.br/ bitstream/123456789/13986/1/InterpretandoMundosJogos.pdf. Acesso em: 09 ago. 2020. 
SANTOS, Bergston Luan; ARRUDA, Eucídio Pimenta. Juventude e videogames: Possibilidades de aprendizagem histórica no Ensino Médio. In: GUIMARÃES, Selva (org.). Ensino de História e Cidadania. Campinas, SP: Papirus, 2016. p. 307-331.

SARTORI, Giovanni. Política. In: SARTORI, Giovanni. Elementos de teoria política. Madrid: Alianza, 1992. p. 205-225.

SILVA, Marcos Antônio da; FONSECA, Selva Guimarães. Ensino de História hoje: errâncias, conquistas e perdas. Revista Brasileira de Historia, São Paulo, v. 31, n. 60 , p. 13-33, 2010. Disponível em: http://www.scielo.br/scielo.php?pid=S0102$01882010000200002 \&$ script $=$ sci_arttext. Acesso em: 10 nov. 2020.

SILVA, Kalina Vanderlei; SILVA, Maciel Henrique. Dicionário de conceitos históricos. 2. ed. São Paulo: Contexto, 2009.

THOMASSON, Amie. Categories, In: ZALTA, Edward Nouri (ed.). The Stanford Encyclopedia of Philosophy. Stanford: Stanford University, 2019. Disponível em: https:// plato.stanford.edu/archives/sum2019/entries/categories. Acesso em: 29 set. 2020.

VIEIRA, Alboni Marisa Dudeque Pianovski; SOUZA JUNIOR, Antônio. A Educação Profissional no Brasil. Revista Interacções, [s. l.], v. 12, n. 40, p. 152-169, 2016. Disponível em: https://revistas.rcaap.pt/interaccoes/article/view/10691/7655. Acesso em 25 ago. 2020.

Texto recebido em 30/09/2020.

Texto aprovado em 25/01/2021. 